\title{
Virtual cellular manufacturing system based on resource element approach and analyzing its performance over different basic layouts
}

\author{
M. Hamedi, N. Ismail, G. R. Esmaeilian and M. K. A. Ariffin
}

Department of Mechanical and Manufacturing Engineering, Faculty of Engineering, University Putra Malaysia 43400, Serdang, Selangor, Malaysia

\begin{tabular}{|c|c|}
\hline A R T I C L E I N F O & A B S T RAC T \\
\hline $\begin{array}{l}\text { Article history: } \\
\text { Received 25 Feb } 2010 \\
\text { Received in revised form } \\
\text { June, 5, } 2011 \\
\text { Accepted } 7 \text { July } 2011 \\
\text { Available online } \\
\text { 9 July 2011 } \\
\text { Keywords: } \\
\text { Manufacturing systems } \\
\text { Virtual cellular Manufacturing } \\
\text { systems } \\
\text { Resource-Element } \\
\text { Functional layout } \\
\text { Distributed Layout } \\
\text { Cell Capacity Utilization }\end{array}$ & $\begin{array}{l}\text { This research aims to present how choosing a suitable layout can improve the performance of } \\
\text { virtual cellular manufacturing systems (VCMSs), especially minimizing the material flow } \\
\text { between machines required by each family group. To present the efficacy of basic layouts on } \\
\text { performances of VCMSs, a multi-objective mathematical model with a goal programming (GP) } \\
\text { approach is developed to generate VCMSs based on resource-elements (REs). The formulated } \\
\text { model is coded in Lingo software and is run over functional and distributed arrangements of the } \\
\text { same machines. The performance and the validity of the developed model are checked by a } \\
\text { numerical example taken from the literature. The objective function of the mathematical model } \\
\text { is measured for that example over two mentioned layout to compare the performance of the } \\
\text { generated systems. Moreover, because of the material handling costs importance, material } \\
\text { flows are measured to find the best option as a basic layout for VCMSs. To compare the } \\
\text { performance of the generated system with the classical cellular manufacturing system (CMS), } \\
\text { cell capacity utilization (CCU) is employed as an independent criterion to evaluate each system. } \\
\text { The result illustrates the priority of distributed layouts for generating RE-based VCMSs } \\
\text { because of its flexibility, minimizing the objective function for the mathematical model, and } \\
\text { smaller material flow by the components. In addition, the generated VCMSs outperforms the } \\
\text { classical CMS from the CCU point of view. }\end{array}$ \\
\hline
\end{tabular}

\section{Introduction}

In classical cellular manufacturing systems (CMSs), machines belonging to each cell are close to each other to minimize the material handling costs and setup times. In such systems, by reconfiguring machine cells the physical location of machines must be changed on the shop floor. Therefore, rearrangement costs may be occurred to systems, and long times must be taken. In addition, doing reconfiguration very frequently may become impractical or even infeasible (Slomp, et al., 2005). Although a cellular layout simplifies workflow and reduces material handling efforts, in dynamic environments with fluctuating demands and unpredictable parts-mix compositions, implementation of CMSs is difficult. It is because a configuration developed for one product-mix may be inefficient in another environment and frequent cell redesigns would be required or significant inter cell flows must

* Corresponding author Tel.: +60389464385

E-mail: maryam.hamedi@gmail.com (M. Hamedi) 
be allowed (Irani, et al., 1993; Khilwani, et al., 2009). To minimize inter cell flows, resource duplication leads to higher investment costs and unbalances in utilization among resources duplicated (Fung, et al., 2008; Lahmar \&Benjaafar, 2005). To reduce the negative implications of CMSs while keeping the positive effects, companies have been encouraged to use virtual cellular manufacturing systems (VCMSs). These systems keep the dynamic nature of systems without any need to physical rearrangement of machines against new arrived orders. In fact, a VCMS, which is predefined by a production control mechanism, is a logical grouping of resources, including machines, workers, and material-handling facilities temporarily for realizing the benefits of classical CMSs to produce jobs divided into part families. This system was appeared for simultaneously using setup efficiency of classical CMSs and the routing efficiency of job shops and does not have any limitation regarding the number and size of families, which are processed. In classical CMSs, the physical location and capacity of a cell are fixed, whereas a virtual cell allows flexible reconfigurations of shop floors in response to changing requirements. Unlike classical CMSs, where each machine belongs to one family, machines can be shared among cells if needed and the common machines are accessible to each of these cells (Khilwani, et al., 2009).

The cell formation, which is the initial step and the most important problem in the design of classical CMSs and VCMSs, consists of making parts family and machines grouping and forming manufacturing cells to process each part family within a virtual or physical cell with minimum distances traveled by parts or maximization of grouping efficacy. This enables any part to be processed within a cell, which has minimum interaction with other cells. The virtual cell formation provides a manufacturing environment, which is flexible, adaptive, and reconfigurable without considerable effort, with the support of a computerized system (Babu, et al., 2000).

The characteristics of manufacturing systems, including design layouts, process plans, and worker skills, are presented by considering machines as entities or defining machining capabilities as entities. The machine-based approach, which is a classical way to define manufacturing systems and their capacities, does not provide sufficient details in describing the shared and unique boundaries between machines. Therefore, in the virtual cells formed by the corresponding methods, there are a number of machines in which not all functions need to be shared, and in the other side, some functions can be shared with more virtual cells (Fung, et al., 2008). In fact, the reasons behind using capabilities of machines instead of machines are increasing machines' utilization because they can perform many different operations, increasing the flexibility, and decreasing the sensitivity to inaccuracies in the demand distribution. In this research, the machines capabilities and parts demands are presented by a resource element (RE) approach.

\subsection{Literature review}

At the start, National Bureau of Standards (NBS) proposed the concept of VCMSs in the 1980s in USA. Whereas the research on VCMSs is still in a preliminary stage, it has gained momentum during the last decade and a wide and diverse variety of solution techniques have been applied mostly for solving part-machine cell formation problems and making schedule for VCMSs, including (Babu, et al., 2000; Drolet, 1989; Fung, et al., 2008; Khilwani, et al., 2009; Ko \& Egbelu, 2003; Mak, et al., 2005; Mak, et al., 2007; Rezazadeh, et al., 2009; Saad, et al., 2002; Slomp, et al., 2005; Xambre \& Vilarinho, 2007). 
Virtual cells are generally generated over a functional layout (Drolet, 1989; Kannan, 1997; Kannan and Ghosh, 1996b; Ko and Egbelu, 2003; Slomp, et al., 2005). Kannan et al.(1998; 1996a, 1996b) studied the performance of virtual cells formed over a functional layout and concluded that these cells could enhance productions performance in volatile manufacturing environments. Fung et al. (2008) focused on developing a model for the virtual cell formation using the RE approach over functional layouts. In the most of the generated VCMSs, the traveling distances of parts in virtual cells have been known as the main disadvantages of them in comparison to the classical one. Therefore, decreasing the traveling distance by use of a suitable layout to generate VCMSs over that is extremely important in the theory and the practice.

It has been discussed in the literature that distributed layouts are very good candidates for the implementation of VCMSs (Baykasoglu, 2003; Benjaafar, et al., 2002; Lahmar \& Benjaafar, 2005). Drolet (1989) illustrated how a distributed layout configuration could be used to form virtual cells that are temporarily dedicated to a job order. Although a distributed layout does not presuppose a cellular structure, it can be served as the basis for one. The advantages of distributed layouts in VCMSs have been encouraged several researchers such as Baykasoglu (2003) and Xambre and Vilarinho (2007) to apply it in the manufacturing systems and others used the properties of this type of layout in their works without calling that as distributed layout including Mak, et al. (2005; 2007). They changed the original layout to the revised layout in such a way that the workstations were widely spread over the production floor as suggested to reduce the material traveling distances in each VCMS. Montreuil et al. (1991) and Benajaafar (1995) proposed the implementation of a scattered layout prior to form virtual cells.

Since VCMSs release companies from the relayout and rearrangement costs, to analyze the effect of the primary arrangement of machines before the formation of virtual cells, this paper focuses on how basic layouts can improve the performance of RE-based VCMSs. Then it provides a comparison between two more usable layouts, functional and distributed, to present although VCMSs can be generated over every arrangement and the developed method in this paper does not have any limitation in this matter, but a VCMS performance is dependent on the basic layout. Therefore, first VCMS will be generated based on REs over a functional layout and second it will be formed over another layout, which has been achieved by distributing the machines of the first layout optimally.

In this paper, machines' arrangement and their capabilities based on REs are considered as the inputs to develop a new model to form virtual cells in a manufacturing system. Since to generate virtual cells multi objectives must be considered, the goal programming (GP) approach has been used to model the problem in the form of a mathematical model.

\section{Mathematical model to form VCMSs based on REs}

In this research, the formation of the VCMS is performed by solving a multi-objective mathematical model, which is a Mixed-Integer Non-Linear Programming (INLP). To present the proposed model, its components including indices, parameters, decision variables, and deviation variables are introduced. Then the closed form of the model with some explanations is brought out.

\subsection{Indices and parameters:}

i: Index for REs, $i \in I, I=\{1,2, \ldots,|I|$

$\mathrm{p}, \mathrm{p}^{\prime}$ : Indices for parts $(\mathrm{C}), \mathrm{p} \in \mathrm{P}, \mathrm{P}=\{1,2, \ldots,|\mathrm{P}|\}$

$\mathrm{n}$ : Index for grids or locations $(\mathrm{G}), \mathrm{n} \in \mathrm{N}, \mathrm{N}=$ $\mathrm{j}$ : Index for virtual cells $(\mathrm{V}), \mathrm{j} \in \mathrm{J}, \mathrm{J}=\{1,2, \ldots,|J|\}$

$\mathrm{m}$ :Index for machines(M), $\mathrm{m} \in \mathrm{M}, \mathrm{M}=\{1,2, \ldots,|\mathrm{M}|\}$

q: Index for goals (GO), $q \in Q=\{1,2, \ldots,|Q|\}$ 
$\{1,2, \ldots,|\mathrm{N}|\}$

$\mathrm{d}_{\mathrm{p}}$ : the demand for component $\mathrm{p}$

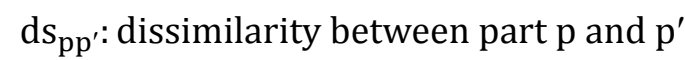

$\mathrm{e}_{\mathrm{m}}$ : Capacity of the $\mathrm{m}-$ th machine

$\mathrm{q}$ : Weight of deviation from $\mathrm{q}-$ th goal

tp: Total time available for doing processes of all components $\varphi$ : A big number

$t_{\mathrm{pi}}$ : Time needed for the $\mathrm{p}-$ th component on the $\mathrm{i}-$ th resource element by machine

$\alpha_{m i}=1$, if the $\mathrm{i}-$ th RE is available on the $\mathrm{m}-$ th machine; 0 , otherwise

$\beta_{p i}=1$, if the component $p$ needs the $i-$ th RE; 0 , otherwise

\subsection{Decision and deviation variables:}

$\mathrm{X}_{\mathrm{pj}}=1$, if $\mathrm{p}-$ th part is assigned to virtual cell j; 0 , otherwise

$\mathrm{U}_{\mathrm{j}}=1$; if virtual cell $\mathrm{j}$ is generated; 0 , otherwise

$\delta \mathrm{m}_{\mathrm{j}}^{-}, \delta \mathrm{m}_{\mathrm{j}}^{+}$: Deviations from the total machine capacity in the $\mathrm{j}-$ th cell;

$\delta_{\mathrm{m}}^{-}, \delta_{\mathrm{m}}^{+}$: Deviation from number of cells which the $\mathrm{m}-$ th machine is assigned ;
$Y_{m j}: 1$, if $m$ - th machine assigned to virtual cell $j$;

0 , otherwise

$\delta_{\mathrm{ds}}^{-}, \delta_{\mathrm{ds}}^{+}$: Under and over achivement of the dissimilari $\delta \mathrm{m}_{\mathrm{ij}}^{-}, \delta \mathrm{m}_{\mathrm{ij}}^{+}$: Deviation from the total machine capacity

- th RE in the $\mathrm{j}$ - th cell;

$\delta_{\mathrm{lo}}^{-}, \delta_{\mathrm{lo}}^{+}$: Under and over achievements of cell loads at 1

The closed form of the mathematical model (objective function and related constraints) is presented here.

$\min \varpi_{1}\left(\delta_{d s}^{-}+\delta_{d s}^{+}\right)+\varpi_{2} \sum_{j=1}^{|J|} \delta m_{j}^{-}+\varpi_{3}\left(\sum_{j=1}^{j} \sum_{i=1}^{|I|} \delta \mathrm{m}_{i j}^{-}\right)+\varpi_{4} \sum_{m=1}^{|M|}\left(\delta_{m}^{+}+\delta_{m}^{-}\right)+\varpi_{5}\left(\delta_{l o}^{-}+\delta_{l o}^{+}\right)$

subject to

$$
\begin{aligned}
& \sum_{j=1}^{|J|} \sum_{p=1}^{|P|} \sum_{p^{\prime}=1}^{|P|} d s_{p p^{\prime}} \times X_{p j} \times X_{p^{\prime} j}+\delta_{d s}^{-}-\delta_{d s}^{+}=0, \\
& \sum_{m=1}^{|M|} Y_{m j} \times e_{m}-\sum_{p=1}^{|P|} \sum_{i=1}^{|I|} X_{p j} \times \beta_{p i} \times t_{p i} \times d_{p}+\delta \mathrm{m}_{j}^{-}-\delta \mathrm{m}_{j}^{+} \geq 0, \quad \forall j \\
& \sum_{m=1}^{|M|} Y_{m j} \times e_{m} \times \alpha_{m i}-\sum_{p=1}^{|P|} X_{p j} \times \beta_{p i} \times t_{p i} \times d_{p}+\delta \mathrm{m}_{i j}^{-}-\delta \mathrm{m}_{i j}^{+} \geq 0, \quad \forall i, j \\
& \sum_{j=1}^{|J|} Y_{m j}+\delta_{m}^{+}-\delta_{m}^{-}=1, \quad \forall m \\
& \sum_{j=1}^{|J|}\left(v c l_{j}-\frac{\sum_{j=1}^{|J|} v c l_{j}}{\sum_{j=1}^{|J|} U_{j}}\right)^{2} \\
& \sum_{j=1}^{|J|} U_{j} \\
& v c l_{j}=\frac{\sum_{j=1}^{|J|} \sum_{p=1}^{|P|} \sum_{i=1}^{|I|} x_{p j} \times \beta_{p i} \times t_{p i} \times d_{p}}{\sum_{m=1}^{|M|} y_{m j}^{\prime} \times e_{m}} \\
& X_{p j}, Y_{m j}^{\prime}, Z_{l} \in\{0,1\},
\end{aligned}
$$


$\delta_{d s}^{-}, \delta_{d s}^{+}, \delta \mathrm{m}_{j}^{-}, \delta \mathrm{m}_{j}^{+}, \delta \mathrm{m}_{i j}^{-}, \delta \mathrm{m}_{i j}^{+}, \delta_{m}^{-}, \delta_{m}^{+}, \delta_{l o}^{-}, \delta_{l o}^{+} \geq 0$

$Y_{m j} \geq U_{j}, \quad \forall m, j$

$X_{p j} \leq U_{j}, \quad \forall p, j$

$X_{p, j} \times \beta_{p i} \leq \sum_{m=1}^{|M|} Y_{m j} \times \alpha_{m i} \quad \forall p, j, i$

$\sum_{j=1}^{|J|} X_{p j}=1 . \quad \forall p$

Eq. (1) presents the objective function of the multi-objective mathematical model, which has been presented by the GP approach; the considered objectives are minimizing the dissimilarity among parts assigned to a virtual cell, minimizing the machines' capacity and the machine-RE capacity shortage in a cell, minimizing machines sharing, and minimizing load-unbalances at machines in virtual cells. Eqs. (2-6) determine goals where Eq. (2) represents dissimilarity goal, Eq. (3) shows machine-capacity goal, Eq. (4) indicates machine RE-capacity goal, Eq. (5) states for machinesharing goal and the load-balancing on cells based on machines is stated in Eq. (6). Eq. (7) calculates loads assigned to each cell in respect to the total capacity of that cell. Eq. (8) and Eq. (9) indicate that the main decision variables can accept only binary values. Eqs. (10-12) show the dependency limitations in such a way that each machine can be assigned to each virtual cell if it is formed, each part can be assigned to a cell only if it is formed, and a part can be assigned to a virtual cell if the RE corresponding to that operation is available in that cell, respectively.

\section{Numerical Example}

This example, which has been taken from Baykasoglu \& Gindy (2000), presents a shop containing 7 types of machines, with one or multiple copies. They used this example to form classical CMS based on machines capabilities. Table 1 presents the number of copies, machine-RE matrix, and the capacity of each machine. The unit of all capacities is minutes per Time Period (TP).

\section{Table 1}

Machines properties of the numerical example

\begin{tabular}{|c|c|c|c|c|c|c|c|c|c|c|c|c|c|}
\hline \multirow{2}{*}{$\begin{array}{l}\text { Machine } \\
\text { types }\end{array}$} & \multirow{2}{*}{ Copies } & \multicolumn{11}{|c|}{ Machine-RE matrix } & \multirow{2}{*}{$\begin{array}{l}\text { Capacity } \\
\text { (Min/TP) }\end{array}$} \\
\hline & & $\overline{\mathrm{RE} 1}$ & RE2 & RE3 & RE4 & RE5 & RE6 & RE7 & $\mathrm{RE}$ & 8RE9 & $\mathrm{RE}$ & 0RE11 & \\
\hline \multirow[t]{2}{*}{1} & 1 & 1 & 0 & 0 & 0 & 0 & 0 & 0 & 0 & 0 & 0 & 0 & 68000 \\
\hline & $2 \mathrm{a}$ & 1 & 1 & 1 & 0 & 0 & 0 & 1 & 1 & 1 & 1 & 1 & 66000 \\
\hline \multirow[t]{2}{*}{2} & $2 b$ & 1 & 1 & 1 & 0 & 0 & 0 & 1 & 1 & 1 & 1 & 1 & 66000 \\
\hline & $2 \mathrm{c}$ & 1 & 1 & 1 & 0 & 0 & 0 & 1 & 1 & 1 & 1 & 1 & 66000 \\
\hline \multirow{2}{*}{3} & $3 a$ & 1 & 1 & 0 & 1 & 0 & 0 & 1 & 0 & 0 & 0 & 0 & 64000 \\
\hline & $3 b$ & 1 & 1 & 0 & 1 & 0 & 0 & 1 & 0 & 0 & 0 & 0 & 64000 \\
\hline \multirow{2}{*}{4} & $4 a$ & 1 & 1 & 0 & 1 & 0 & 0 & 1 & 0 & 0 & 1 & 0 & 64000 \\
\hline & $4 b$ & 1 & 1 & 0 & 1 & 0 & 0 & 1 & 0 & 0 & 1 & 0 & 64000 \\
\hline \multirow{2}{*}{5} & $5 a$ & 0 & 0 & 0 & 0 & 1 & 1 & 0 & 0 & 0 & 0 & 0 & 64000 \\
\hline & $5 b$ & 0 & 0 & 0 & 0 & 1 & 1 & 0 & 0 & 0 & 0 & 0 & 64000 \\
\hline 6 & 6 & 0 & 0 & 0 & 0 & 0 & 1 & 0 & 0 & 0 & 0 & 0 & 65000 \\
\hline 7 & 7 & 0 & 0 & 0 & 0 & 1 & 0 & 0 & 0 & 0 & 0 & 0 & 64000 \\
\hline
\end{tabular}


According to Baykasoglu \& Gindy (2000), 20 parts are proceed by 11 REs. The part-RE relation in the form of a 0-1 matrix is imported to the Lingo software. Table 2 demonstrates the parts properties, including the part-RE matrix, the part processing and set-up time, the demand per each part, and the load of each part in the system, which is calculated by multiplying the demand of each part and the summation of the processing times $\left(\mathrm{d}_{\mathrm{p}} \times \sum_{\mathrm{i}=1}^{|\mathrm{I}|} \mathrm{t}_{\mathrm{pi}}\right)$. For example, for the first part, the total time $(6+8+9=23)$ multiplied by the demand value $(3000)$ resulted in a load equal to 69000 .

\section{Table 2}

Parts properties of the numerical example

\begin{tabular}{llllllllllll|llllllllllllll}
\hline Parts & & 1 & 2 & 3 & 4 & 5 & 6 & 7 & 8 & 9 & 10 & 11 & 1 & 2 & 3 & 4 & 5 & 6 & 7 & 8 & 9 & 10 & 11 & (units/ TP) & (min) \\
\hline 1 & 1 & 1 & 0 & 1 & 0 & 0 & 0 & 0 & 0 & 0 & 0 & 6 & 8 & 0 & 9 & 0 & 0 & 0 & 0 & 0 & 0 & 0 & 3000 & 69000 \\
2 & 1 & 1 & 1 & 0 & 0 & 0 & 0 & 0 & 0 & 0 & 0 & 5 & 6 & 4 & 0 & 0 & 0 & 0 & 0 & 0 & 0 & 0 & 1000 & 15000 \\
3 & 0 & 0 & 0 & 0 & 1 & 1 & 1 & 0 & 0 & 0 & 0 & 0 & 0 & 0 & 0 & 2 & 6 & 8 & 0 & 0 & 0 & 0 & 2500 & 40000 \\
4 & 0 & 0 & 0 & 0 & 1 & 0 & 0 & 1 & 0 & 0 & 0 & 0 & 0 & 0 & 0 & 4 & 0 & 0 & 5 & 0 & 0 & 0 & 1520 & 13680 \\
5 & 0 & 0 & 0 & 1 & 1 & 0 & 1 & 0 & 0 & 0 & 0 & 0 & 0 & 0 & 5 & 6 & 0 & 8 & 0 & 0 & 0 & 0 & 1480 & 28120 \\
6 & 0 & 0 & 0 & 0 & 0 & 1 & 1 & 1 & 0 & 0 & 0 & 0 & 0 & 0 & 0 & 0 & 5 & 5 & 6 & 0 & 0 & 0 & 3500 & 56000 \\
7 & 0 & 0 & 0 & 0 & 0 & 0 & 0 & 1 & 1 & 1 & 0 & 0 & 0 & 0 & 0 & 0 & 0 & 0 & 7 & 7 & 8 & 0 & 1000 & 22000 \\
8 & 0 & 0 & 0 & 0 & 0 & 0 & 0 & 0 & 1 & 1 & 1 & 0 & 0 & 0 & 0 & 0 & 0 & 0 & 0 & 6 & 5 & 9 & 2000 & 40000 \\
9 & 1 & 1 & 0 & 0 & 1 & 0 & 0 & 0 & 0 & 0 & 0 & 7 & 5 & 0 & 0 & 3 & 0 & 0 & 0 & 0 & 0 & 0 & 3000 & 45000 \\
10 & 0 & 0 & 1 & 1 & 0 & 0 & 0 & 0 & 0 & 0 & 0 & 0 & 0 & 4 & 5 & 0 & 0 & 0 & 0 & 0 & 0 & 0 & 2000 & 18000 \\
11 & 0 & 0 & 0 & 0 & 1 & 1 & 0 & 0 & 1 & 0 & 0 & 0 & 0 & 0 & 0 & 5 & 5 & 0 & 0 & 4 & 0 & 0 & 4500 & 63000 \\
12 & 0 & 0 & 0 & 0 & 0 & 0 & 0 & 1 & 1 & 1 & 0 & 0 & 0 & 0 & 0 & 0 & 0 & 0 & 7 & 8 & 8 & 0 & 1000 & 23000 \\
13 & 0 & 0 & 0 & 0 & 1 & 0 & 0 & 1 & 0 & 1 & 0 & 0 & 0 & 0 & 0 & 1 & 0 & 0 & 3 & 0 & 5 & 0 & 3000 & 27000 \\
14 & 0 & 0 & 0 & 0 & 1 & 0 & 1 & 1 & 0 & 0 & 0 & 0 & 0 & 0 & 0 & 5 & 0 & 4 & 5 & 0 & 0 & 0 & 2500 & 35000 \\
15 & 1 & 1 & 0 & 0 & 0 & 0 & 0 & 0 & 0 & 0 & 0 & 6 & 2 & 0 & 0 & 0 & 0 & 0 & 0 & 0 & 0 & 0 & 2500 & 20000 \\
16 & 0 & 0 & 1 & 1 & 0 & 0 & 0 & 0 & 0 & 0 & 0 & 0 & 0 & 6 & 3 & 0 & 0 & 0 & 0 & 0 & 0 & 0 & 1900 & 17100 \\
17 & 0 & 0 & 0 & 0 & 0 & 1 & 1 & 1 & 0 & 0 & 0 & 0 & 0 & 0 & 0 & 0 & 4 & 5 & 7 & 0 & 0 & 0 & 2400 & 38400 \\
18 & 0 & 0 & 0 & 0 & 0 & 0 & 0 & 1 & 1 & 1 & 1 & 0 & 0 & 0 & 0 & 0 & 0 & 0 & 5 & 5 & 5 & 2 & 1200 & 20400 \\
19 & 0 & 1 & 0 & 0 & 1 & 0 & 0 & 0 & 0 & 0 & 0 & 0 & 5 & 0 & 0 & 5 & 0 & 0 & 0 & 0 & 0 & 0 & 1300 & 13000 \\
20 & 0 & 0 & 0 & 0 & 0 & 0 & 1 & 1 & 1 & 0 & 0 & 0 & 0 & 0 & 0 & 0 & 0 & 1 & 5 & 3 & 0 & 0 & 3000 & 27000 \\
\hline
\end{tabular}

Since to develop a VCMS, a basic arrangement must be considered, Fig. 1 depictures the first physical arrangements of machines in the form of a functional layout taken from Baykasoglu \& Gindy (2000) and a distributed layout. The number of machines presents the machines located in each functional area. In Fig. 1 (a), heavy solid lines draw the borders of the same departments.

\begin{tabular}{|l|l|l|}
\hline M 2a & M 2b & M 1 \\
\hline M 2c & M 3a & M 3b \\
\hline M 4a & M 4b & M 5a \\
\hline M 6 & M 7 & M 5b \\
\hline
\end{tabular}

1(a) the first arrangement of machines (Functional Layout)

\begin{tabular}{|l|l|l|}
\hline M 4a & M 3a & M2a \\
\hline M 2b & M 6 & M 7 \\
\hline M 1 & M 2c & M 3b \\
\hline M 4b & M 5a & M 5b \\
\hline
\end{tabular}

1(b) the second arrangement of machines (distributed layout)

Fig. 1. The basic arrangement of machines of the numerical example 
The developed mathematical model to form VCMSs has been coded by Lingo as a powerful software for optimization problems. Parts are grouped and families formed considering their similarities and constraints of the model simultaneously with grouping machines and assigning them to cells. Baykasoglu \& Gindy (2000) solved this problem by considering the maximum and minimum number of parts and machines equal to 9,4 and 5,3, respectively. Therefore, the same values for these parameters are considered as the inputs of the model. After entering the functional layout (Fig. 1(a)) as the first location of machines to Lingo software, the result of grouping components and machines, and assigning them to the formed virtual cells by the developed mathematical model is presented in Table 3. The same process is repeated for the case of distributed layout (Fig. 1(b)) as the basic layout, which the result is provided in Table 4.

\section{Table 3}

The RE-based VCMS generate over the functional layout

\begin{tabular}{|c|c|c|c|c|c|c|c|c|c|c|c|c|}
\hline Cells & \multicolumn{8}{|c|}{ Parts assignment } & \multicolumn{4}{|c|}{ Machines assignment } \\
\hline 1 & P7 & P8 & P12 & P13 & P18 & P20 & & & $2 \mathrm{c}$ & $3 a$ & $4 a$ & 7 \\
\hline 2 & P3 & P4 & P5 & P6 & P14 & P17 & & & $2 \mathrm{a}$ & $4 b$ & $5 a$ & 6 \\
\hline 3 & $\mathrm{P} 1$ & $\mathrm{P} 2$ & P9 & P10 & P11 & P15 & P16 & P19 & 1 & $2 b$ & $3 b$ & $5 b$ \\
\hline
\end{tabular}

\section{Table 4}

The RE-based VCMS generate over the distributed layout

\begin{tabular}{|c|c|c|c|c|c|c|c|c|c|c|c|}
\hline Cells & \multicolumn{5}{|c|}{ Parts assignment } & \multicolumn{6}{|c|}{ Machines assignment } \\
\hline 1 & P7 & P8 & P11 & P12 & P13 & P18 & P20 & 1 & $2 a$ & $3 a$ & $5 b$ \\
\hline 2 & P1 & P2 & P9 & $\mathrm{P} 10$ & P15 & P16 & P19 & $2 \mathrm{c}$ & $3 b$ & $4 a$ & $5 \mathrm{a}$ \\
\hline 3 & P3 & P4 & P5 & P6 & P14 & P17 & & $2 b$ & $4 b$ & 6 & 7 \\
\hline
\end{tabular}

The outputs of the developed mathematical model presents that in the first case by considering the functional layout as the basic, the optimum objective function is equal to 160.6344 achieved after 11557 iterations. In the second case by considering the distributed layout as the basic, this value is 155.9084, which was found after 8879 iterations. Whatever the objective function in latter case is smaller than the first one, to make a better judgment in this matter, the traveled distances and consequently the material flows are also measured as the second performance criterion. Since the developed mathematical model is based on design issues not operational, it determines each part is assigned to which cell. By considering the machines assigned to each cell, the route, where each part travels, can be forecasted. In some parts, where more than one route is possible, traveled distances and material flows are shown as the minimum and maximum.

Table 5 and 6 present the parts specifications, including demands, sequencing, and boundary of material flows for the functional and distributed layouts. By comparing the minimum and maximum material flows that components traveled in the VCMS generated over the functional layout (92640, $165180)$ in Table 5 and the distributed layout $(58520,17680)$ in Table 6 , it seems that by using an optimum scheduling, distributed layouts have more potential to achieve smaller minimum material flows.

To compare the VCMSs developed by the mathematical model in this paper and the original CMS by Baykasoglu \& Gindy (2000), its output needs to be translated to an independent criterion from the developed model in this paper. Since Baykasoglu \& Gindy (2000) illustrated the validity of their model based on the cell capacity utilization (CCU), this criterion is calculated for the both VCMSs 
generated over two mentioned layouts. According to Baykasoglu \& Gindy (2000), CCU is calculated by dividing the total load in a cell by its capacity. The total load on each machine is the summation of the total processing time requirements from each machine presented in the last column of Table 2. The capacity of a cell is calculated by summing its machines capacities. By use of a mathematical model, they generated a CMS including three classical cells. The output of their model, including parts assignment, machine assignment, and the CCU belonging to each cell, has been presented in Table 7.

\section{Table 5}

Material flow in the VCMS generated over the functional layout

\begin{tabular}{llllll}
\hline Part & Sequence & Seq. Min. Dis. & Min. Dis. Seq. Max. Dis. Max. Dis. Demand
\end{tabular}

\begin{tabular}{|c|c|c|c|c|c|c|}
\hline 1 & $1,2,4$ & $3 b, 3 b, 3 b$ & 0 & $3 b, 2 b, 3 b$ & 12000 & 3000 \\
\hline 2 & $1,2,3$ & $2 b, 2 b, 2 b$ & 0 & $2 b, 3 b, 2 b$ & 4000 & 1000 \\
\hline 3 & $3,6,7$ & $2 a, 6,4 b$ & 12500 & $2 \mathrm{a}, 5 \mathrm{a}, 2 \mathrm{a}$ & 20000 & 2500 \\
\hline 4 & 5,8 & $5 \mathrm{a}, 2 \mathrm{a}$ & 6080 & $5 \mathrm{a}, 2 \mathrm{a}$ & 6080 & 1520 \\
\hline 5 & $4,5,7$ & $4 b, 5 a, 4 b$ & 2960 & $4 b, 5 a, 2 a$ & 7400 & 1480 \\
\hline 6 & $6,7,8$ & $6,2 a, 2 a$ & 10500 & $6,4 b, 2 a$ & 17500 & 3500 \\
\hline 7 & $8,9,10$ & $2 \mathrm{c}, 2 \mathrm{c}, 2 \mathrm{c}$ & 0 & $2 \mathrm{c}, 2 \mathrm{c}, 4 \mathrm{a}$ & 1000 & 1000 \\
\hline 8 & $9,10,11$ & $2 \mathrm{c}, 2 \mathrm{c}, 2 \mathrm{c}$ & 0 & $2 \mathrm{c}, 4 \mathrm{~b}, 2 \mathrm{c}$ & 4000 & 2000 \\
\hline 9 & $1,2,5$ & $3 b, 3 b, 5 b$ & 6000 & $3 b, 2 b, 5 b$ & 18000 & 3000 \\
\hline 10 & 3,4 & $2 b, 3 b$ & 4000 & $2 b, 3 b$ & 4000 & 2000 \\
\hline 11 & $5,6,9$ & $5 b, 5 b, 2 b$ & 18000 & $5 b, 5 b, 2 b$ & 18000 & 4500 \\
\hline 12 & $8,9,10$ & $2 \mathrm{c}, 2 \mathrm{c}, 2 \mathrm{c}$ & 0 & $2 \mathrm{c}, 2 \mathrm{c}, 4 \mathrm{a}$ & 1000 & 1000 \\
\hline 13 & $5,8,10$ & $7,2 \mathrm{c}, 2 \mathrm{c}$ & 9000 & $7,2 c, 4 a$ & 12000 & 3000 \\
\hline 14 & $5,7,8$ & $5 a, 4 b, 2 a$ & 10000 & $5 a, 4 b, 2 a$ & 10000 & 2500 \\
\hline 15 & 1,2 & $2 b, 2 b$ & 0 & $3 b, 2 b$ & 5000 & 2500 \\
\hline 16 & 3,4 & $2 b, 3 b$ & 3800 & $2 b, 3 b$ & 3800 & 1900 \\
\hline 17 & $6,7,8$ & $6,2 a, 2 a$ & 7200 & $6,4 b, 2 a$ & 12000 & 2400 \\
\hline 18 & $8,9,10$ & $2 \mathrm{c}, 2 \mathrm{c}, 2 \mathrm{c}$ & 0 & $2 \mathrm{c}, 2 \mathrm{c}, 4 \mathrm{a}$ & 1200 & 1200 \\
\hline 19 & 2,5 & $3 b, 5 b$ & 2600 & $2 b, 5 b$ & 5200 & 1300 \\
\hline 20 & $7,8,9$ & $2 \mathrm{c}, 2 \mathrm{c}, 2 \mathrm{c}$ & 0 & $3 a, 2 c, 2 c$ & 3000 & 3000 \\
\hline- & Total & $* * * * * * * * * * *$ & 92640 & $* * * * * * * * * * *$ & 165180 & $* * * * * * * * * * * *$ \\
\hline
\end{tabular}


Table 6

Material flow in the VCMS generated over the distributed layout

Part Sequence Seq. Min. Dis. Min. Dis. *D Seq. Max. Dis. Max. Dis.* D Demand (D)

\begin{tabular}{|c|c|c|c|c|c|c|}
\hline 1 & $1,2,4$ & $3 b, 3 b, 3 b$ & 0 & $3 b, 4 a, 3 b$ & 24000 & 3000 \\
\hline 2 & $1,2,3$ & $2 \mathrm{c}, 2 \mathrm{c}, 2 \mathrm{c}$ & 0 & $3 b, 4 a, 2 c$ & 7000 & 1000 \\
\hline 3 & $3,6,7$ & $2 b, 6,2 b$ & 5000 & $2 b, 6,4 b$ & 10000 & 2500 \\
\hline 4 & 5,8 & $7,2 \mathrm{~b}$ & 3040 & $7,2 b$ & 3040 & 1520 \\
\hline 5 & $4,5,7$ & $4 b, 7,2 b$ & 8880 & $4 b, 7,4 b$ & 11840 & 1480 \\
\hline 6 & $6,7,8$ & $6,2 b, 2 b$ & 3500 & $6,4 b, 2 b$ & 17500 & 3500 \\
\hline 7 & $8,9,10$ & $2 \mathrm{a}, 2 \mathrm{a}, 2 \mathrm{a}$ & 0 & $2 \mathrm{~b}, 2 \mathrm{a}, 2 \mathrm{a}$ & 0 & 1000 \\
\hline 8 & $9,10,11$ & $2 \mathrm{a}, 2 \mathrm{a}, 2 \mathrm{a}$ & 0 & $2 \mathrm{~b}, 2 \mathrm{a}, 2 \mathrm{a}$ & 0 & 2000 \\
\hline 9 & $1,2,5$ & $2 \mathrm{c}, 2 \mathrm{c}, 5 \mathrm{a}$ & 3000 & $3 b, 4 a, 5 a$ & 24000 & 3000 \\
\hline 10 & 3,4 & $2 c, 3 b$ & 2000 & $2 \mathrm{c}, 4 \mathrm{a}$ & 6000 & 2000 \\
\hline 11 & $5,6,9$ & $5 b, 5 b, 2 a$ & 13500 & $5 b, 5 b, 2 a$ & 13500 & 4500 \\
\hline 12 & $8,9,10$ & $2 \mathrm{a}, 2 \mathrm{a}, 2 \mathrm{a}$ & 0 & $2 \mathrm{a}, 2 \mathrm{a}, 2 \mathrm{a}$ & 0 & 1000 \\
\hline 13 & $5,8,10$ & $5 \mathrm{~b}, 2 \mathrm{a}, 2 \mathrm{a}$ & 9000 & $5 \mathrm{~b}, 2 \mathrm{a}, 2 \mathrm{a}$ & 9000 & 3000 \\
\hline 14 & $5,7,8$ & $7,2 b, 2 b$ & 5000 & $7,4 b, 2 b$ & 15000 & 2500 \\
\hline 15 & 1,2 & $4 a, 4 a$ & 0 & $4 a, 3 b$ & 10000 & 2500 \\
\hline 16 & 3,4 & $2 c, 3 b$ & 1900 & $2 \mathrm{c}, 4 \mathrm{a}$ & 5700 & 1900 \\
\hline 17 & $6,7,8$ & $6,2 b, 2 b$ & 2400 & $6,4 b, 2 b$ & 12000 & 2400 \\
\hline 18 & $8,9,10$ & $2 \mathrm{a}, 2 \mathrm{a}, 2 \mathrm{a}$ & 0 & $2 \mathrm{a}, 2 \mathrm{a}, 2 \mathrm{a}$ & 0 & 1200 \\
\hline 19 & 2,5 & $2 c, 5 a$ & 1300 & $4 a, 5 a$ & 5200 & 1300 \\
\hline 20 & $7,8,9$ & $2 \mathrm{a}, 2 \mathrm{a}, 2 \mathrm{a}$ & 0 & $3 a, 2 a, 2 a$ & 3000 & 3000 \\
\hline - & Total & ************* & 58520 & $* * * * * * * * * * *$ & 17680 & $* * * * *$ \\
\hline
\end{tabular}

Table 7

The CMS developed by Baykasoglu \& Gindy (2000)

\begin{tabular}{cllllllllllllllllll} 
Cells & \multicolumn{4}{c}{ The part assignment } & \multicolumn{4}{c}{ The machine assignment } & CCU & Summation of CCUs & Average of CCUs \\
\hline Cell 1 & 4 & 7 & 8 & 12 & 13 & 18 & & 1 & $2 a$ & 7 & & 0.74 & & \\
Cell 2 & 1 & 2 & 9 & 10 & 15 & 16 & 19 & $3 a$ & $5 a$ & $4 a$ & $2 b$ & 0.76 & 2.39 & 0.796667
\end{tabular}

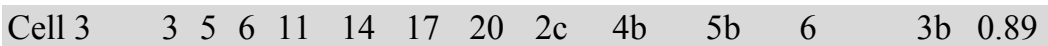


The CCU for the outputs of the multi-objective mathematical model for the numerical example is shown in Table 8. As it would appear from comparing Tables 7 and 8, the VCMS generated by the mathematical model developed over the distributed layout absolutely leads to better CCUs in comparison to the CMS, even if they are compared cell by cell. Moreover, by considering the average and the summation of the CCUs, the developed VCMSs outperform the CMS. In addition, comparing the VCMSs generated over the distributed layout and the functional layout in Table 8 confirms that their performances are close to each other in the CCU point of view. However, the VCMS generated over the distributed layout leads to smaller objective function and smaller material flows.

\section{Table 8}

CCUs for the VCMSs by the mathematical model over two layouts of Example 1 The basic arrangement The functional layout The distributed layout

\begin{tabular}{lllllll}
\hline Cells & 1 & 2 & 3 & 1 & 2 & 3 \\
\hline Loads & 159400 & 211200 & 260100 & 222400 & 197100 & 211200 \\
Capacities & 258000 & 259000 & 262000 & 262000 & 258000 & 259000 \\
CCU & 0.617829 & 0.815444 & 0.992748 & 0.848855 & 0.763953 & 0.815444 \\
Summation of CCUs & 2.426 & & & 2.428 & & \\
Average CCU & 0.808 & & & 0.809 & & \\
\hline
\end{tabular}

\section{Conclusion}

In this study, a new mathematical model has been developed to form VCMSs based on Res and their performances were measured over two different types of basic layouts. To design virtual cells, machines independent capabilities known as REs were considered to define processing requirements of the parts and processing capabilities of machines. Therefore, the overlapping capabilities among machines and optional machines to process components were considered automatically to improve the results. Generating virtual cells was done by developing a mathematical model with the GP approach for the part-machine virtual cell formation problem, which grouped parts and machines and designed virtual cells simultaneously.

To check the validity of the developed methodology, it was tested over a numerical example taken from the literature including two types of layouts, functional and distributed. The VCMS is generated over the basic arrangements of the example and evaluated based on two criteria: the defined objective function in the mathematical model and the total material flows during their processes. The results illustrated that the VCMS generated over the distributed layout has better performances i.e. smaller amounts for the objective function and the material flows, compared with the VCMS generated over the functional layout. Therefore, implementing VCMSs over distributed layouts can be considered as a successful solution for companies working in a highly volatile manufacturing environment, but it will not force managers to change the current layouts of their companies if it is not economical. In other words, companies can take advantages of VCMSs over any basic layout. Moreover, the priority of VCMSs over classical CMSs presented based on the cell capacity utilization (CCU) so that virtual cells lead to higher CCUs. 


\section{Acknowledgment}

The authors gratefully acknowledge the financial support of the ministry of higher education of Malaysia, under the FRGS 03-04-10-790FR and University Putra Malaysia (UPM).

\section{References}

Babu, A. S., Nandurkar, K. N., \& Thomas, A. (2000). Development of virtual cellular manufacturing systems for SMEs. Logistics Information Management, 13 (4), 228-242.

Baykasoglu, A. (2003). Capability-based distributed layout approach for virtual manufacturing cells. International Journal of Production Research, 41(11), 2597-2618.

Baykasoglu, A., \& Gindy, N. N. Z. (2000). MOCACEF 1.0: Multiple objective capability based approach to form part-machine groups for cellular manufacturing applications. International Journal of Production Research, 38(5), 1133-1161.

Benajaafar, S. (1995). Design of flexible layouts for manufacturing systems. Paper presented at the 95 Engineering Management Conference, Global Engineering Management: Emerging Trends in the Asia Pacific.

Benjaafar, S., Heragu, S. S., \& Irani, S. A. (2002). Next generation factory layouts: Research challenges and recent progress. Interfaces, 32(6), 58-76.

Drolet, J. R. (1989). Scheduling virtual cellular manufacturing systems. Unpublished Ph.D. Thesis, Purdue University, West Lafayette, IN.

Fung, R. Y. K., Liang, F., Jiang, Z., \& Wong, T. N. (2008). A multi-stage methodology for virtual cell formation oriented agile manufacturing. International Journal of Advance Manufacturing Technology, 36, 798-810.

Irani, S. A., Cayalier, T. M., \& Cohen, P. H. (1993). Virtual manufacturing cells: exploiting layout design and intercell flows for the machine sharing problem. International Journal of Production Research, 31(4), 791-810.

Kannan, V. R. (1997). A simulation analysis of the impact of family configuration on virtual cellular manufacturing. Production Planning \& Control, 8(1), 14-24.

Kannan, V. R. (1998). Analysing the trade-off between efficiency and flexibility in cellular manufacturing systems. Production Planning \& Control, 9(6), 572-579.

Kannan, V. R., \& Ghosh, S. (1996a). Cellular manufacturing using virtual cells. International Journal of Operations \& Production Management, 16(5), 99-112.

Kannan, V. R., \& Ghosh, S. (1996b). A virtual cellular manufacturing approach to batch production. Decision Sciences, 27(3), 519-539.

Khilwani, N., Ulutas, B. H., Islier, A. A., \& Tiwari, M. K. (2009). A methodology to design virtual cellular manufacturing systems. Journal of Intelligent Manufacturing, 1-12. DOI 10.1007/s10845009-0314-6.

Ko, K.-C., \& Egbelu, P. J. (2003). Virtual cell formation. International Journal of Production Research, 41(11), 2365-2389.

Lahmar, M., \& Benjaafar, S. (2005). Design of distributed layouts. IIE Transactions, 37(4), 303-318.

Mak, K. L., Lau, J. S. K., \& Wang, X. X. (2005). A genetic scheduling methodology for virtual cellular manufacturing systems: an industrial application. International Journal of Production Research, 43(12), 2423-2450.

Mak, K. L., Peng, P., Wang, X. X., \& Lau, T. L. (2007). An ant colony optimization algorithm for scheduling virtual cellular manufacturing systems. International Journal of Computer Integrated Manufacturing, 20(6), 524 - 537.

Montreuil, B., Venkatadri, U., \& Lefrancois, P. (1991). Holographic layout of manufacturing systems. Paper presented at the 19th IIE Systems Integration Conference, Orlando, Florida, USA.

Rezazadeh, H., Ghazanfari, M., Sadjadi, S. J., Aryanezhad, M. B., \& Makui, A. (2009). Linear programming embedded particle swarm optimization for solving an extended model of dynamic 
virtual cellular manufacturing systems. Journal of Applied Research and Technology, 7 (1), 83108.

Saad, S. M., Baykasoglu, A., \& Gindy, N. N. Z. (2002). An integrated framework for reconfiguration of cellular manufacturing systems using virtual cells. Production Planning \& Control, 13(4), 381393.

Slomp, J., Chowdary, B. V., \& Suresh, N. C. (2005). Design of virtual manufacturing cells: a mathematical programming approach. Robotics and Computer-Integrated Manufacturing, 21, 273288.

Xambre, A. R., \& Vilarinho, P. M. (2007). Virtual Manufacturing Cell Formation Problem (VMCFP) In a Distributed Layout. Paper presented at the ICPR19 - 19th International Conference on Production Research, Valparaiso, Chile. 